\title{
Corrosion inhibition of 1-vinylimidazole-3-phenacyl hexafluoroantimonate salt on mild steel in $\mathrm{HCl}$ solution ${ }^{1}$
}

\author{
A. Nahlé,* I. Abu-Abdoun and I. Abdel-Rahman \\ Department of Chemistry, College of Sciences, University of Sharjah, Sharjah, \\ P.O. Box: 27272, United Arab Emirates \\ *E-mail: anahle@sharjah.ac.ae
}

\begin{abstract}
The purpose of this paper is to study by weight loss experiments the effect of 1vinylimidazole-3-phenacyl hexafluoroantimonate salt (VIPFA) on the corrosion inhibition of mild steel in $1.0 \mathrm{M} \mathrm{HCl}$ solution. Weight loss measurements were carried out on mild steel specimens in $1.0 \mathrm{M} \mathrm{HCl}$ and in $1.0 \mathrm{M} \mathrm{HCl}$ containing various concentrations $\left(5.0 \cdot 10^{-4}\right.$ to $\left.5 \cdot 10^{-7} \mathrm{M}\right)$ of the laboratory synthesized 1-vinylimidazole-3-phenacyl hexafluoroantimonate salt at temperatures ranging from 303 to $343 \mathrm{~K}$. 1-Vinylimidazole-3-phenacyl hexafluoroantimonate salt (VIPFA) was found to be a very efficient inhibitor for carbon steel in $1.0 \mathrm{M} \mathrm{HCl}$ solution, reaching about 92 per cent at the concentration of $5.0 \cdot 10^{-4} \mathrm{M}$ at $303 \mathrm{~K}$. The percentage of inhibition in the presence of this inhibitor was decreased with temperature which indicates that physical adsorption was the predominant inhibition mechanism because the quantity of adsorbed inhibitor decreases with increasing temperature. From this study, it was concluded that this inhibitor could have application in industries, where hydrochloric acid solutions at elevated temperatures are used to remove scale and salts from steel surfaces, such as acid cleaning of tankage and pipeline, and may render dismantling unnecessary.
\end{abstract}

Key words: corrosion, inhibitor, 1-vinylimidazole-3-phenacyl hexafluoroantimonate, Temkin adsorption isotherm.

Received: July 02, 2015.

doi: $\underline{10.17675 / 2305-6894-2015-4-3-255-268}$

\section{Introduction}

Corrosion increases running costs and reduces plant efficiency, availability, and product quality. The corrosion inhibition of mild steel in aggressive acidic solutions has been widely investigated. In industries, hydrochloric acid solutions are often used in order to remove scale and salts from steel surfaces, and cleaning tanks and pipelines. This treatment may be prerequisite for coating by electroplating, galvanizing or painting techniques. The acid must be treated to prevent an extensive dissolution of the underlying metal. This treatment involves the addition of some organic inhibitors to the acid solution that adsorb

\footnotetext{
${ }^{1}$ Note from the Editors: The opinion of the authors that it is valid to calculate the degree of surface coverage by an inhibitor from corrosion data for compounds affecting the activation energy of corrosion does not fully agree with the views of the Editorial Board explained in detail in Int. J. Corros. Scale Inhib., 2015, 4, no. 2, 108.
} 
at the metal/solution interface by displacing water molecules on the surface and forming a compact barrier film.

Most organic inhibitors are organic compounds that contain $\mathrm{N}, \mathrm{P}, \mathrm{S}$, and $\mathrm{OH}$ polar groups and can be strongly adsorbed on the metal surface [1,2]. These inhibitors are known to be similar to catalytic poisons, as they decrease the reaction rate at the metal/solution interface without, in general, being involved in the reaction considered. The mechanism by which an inhibitor decreases the corrosion current is achieved by interfering with some of the steps for the electrochemical process. Adsorption of inhibitor on the metal surface will change the structure of the electric double layer. The adsorption itself depends to a great extent on the molecular structure [3].

The inhibition efficiency was reported to be improved predominantly by increasing the molecular surface area and is influenced by the position of the substituents [4-6]. For planar molecules with very similar molecular surface areas the adsorption properties are also function of the electronic structure of the molecule [7].

The development of new corrosion inhibitors of non-toxic nature, which do not contain heavy metals and organic phosphates, is very important [8]. Because of their environmentally friendly characteristics in addition to their unique properties, imidazolium salts are expected to be good corrosion inhibitors [9-11].

Many authors have used various nitrogen-containing compounds in their corrosion inhibition investigations [12-20, 36-38]. Other authors [21-32] have studied imidazolium salt as corrosion inhibitors for metals in aggressive media. In all these studies, the nitrogen atom(s) in the compounds showed to be able to absorb very well on the metal surface and form protective layer, which in turns increased the corrosion inhibition with the increase in the concentration of the inhibitor, in some cases reaching 99\% inhibition [14].

No studies have been reported on 1-vinylimidazole-3-phenacyl hexafluoroantimonate salt (VIPFA) (Scheme 1), in terms of studying the temperature effect on the corrosion inhibition of mild steel in 1.0 M HCl solution. Mild steel was chosen in our studies since high temperature aggressive acids are widely used in industries in connection to mild and low alloy steels.
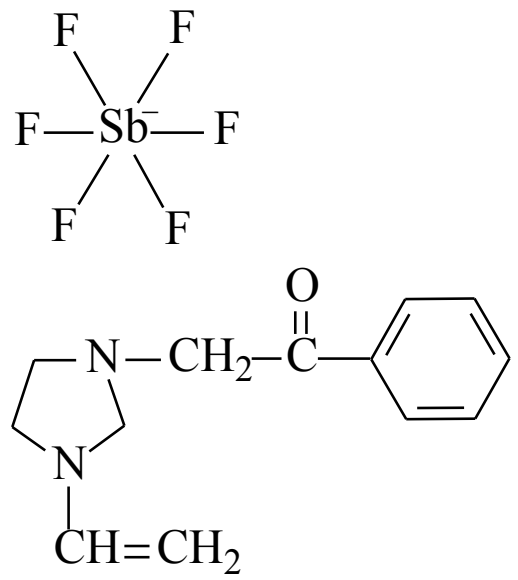

Scheme 1. 1-Vinylimidazole-3-phenacyl hexafluoroantimonate salt (VIPFA) 


\section{Experimental details}

\section{Synthesis of 1-vinylimidazole-3-phenacyl hexafluoroantimonate}

The phenacylimidazoluim salt (3) (Scheme 2) was prepared by refluxing an equimolar mixture of the 1-vinylmidazole and phenacyl bromide (2) in acetone as follows: $2.50 \mathrm{~mL}$ $(0.027 \mathrm{~mol})$ of vinylimidazole (1) and $4.60 \mathrm{~g}$ of phenacylbromide $(0.023 \mathrm{~mol})$ (2) in $100 \mathrm{~mL}$ acetone was refluxed for two hours. After cooling to room temperature, a crystalline solid of salt (3) was collected by filtration, then washed with excess diethyl ether and dried.

The bromide salt (3) was converted to the hexafluoroantimonate by treatment with potassium hexafluoroantimonate $\left(\mathrm{KSbF}_{6}\right)$ in methanol/water mixture $(70 / 30) \%$ by volume. After stirring for 20 minutes, the reaction product was filtered, washed several times with water, then with diethyl ether and dried under vacuum at room temperature. Dissolution in chloroform and addition of excess diethyl ether gave the pure hexafluoroantimonate salt in 85 percent yield.

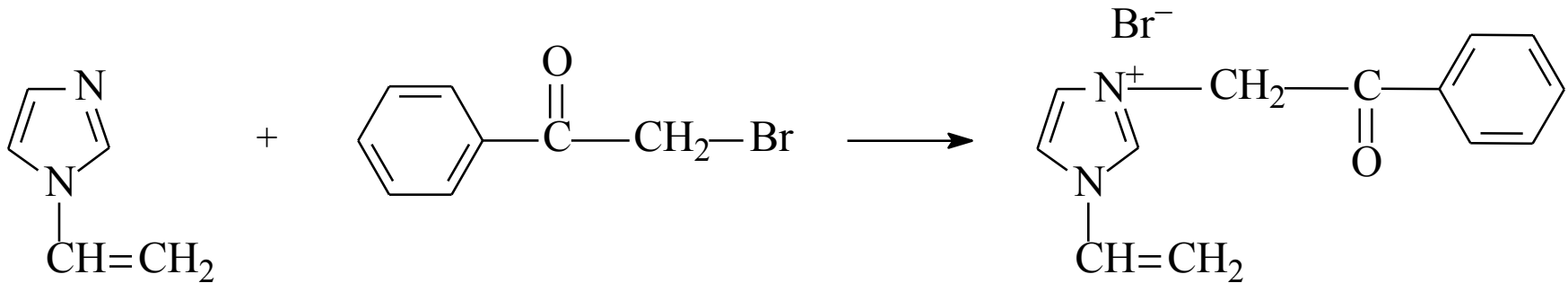

(1)

(2)

Scheme 2. Synthesis of 1-vinylimidazole-3-phenacyl hexafluoroantimonate.

\section{Specimen preparation}

For the weight loss measurements, rectangular specimens $(1 \mathrm{~cm} \times 2.3 \mathrm{~cm} \times 0.3 \mathrm{~cm})$ cut from large sheet of $3 \mathrm{~mm}$ thick mild steel (IS 226 containing $0.18 \% \mathrm{C}, 0.6 \% \mathrm{Mn}$, and $0.35 \% \mathrm{Si}$ ) supplied by "Reliable Steel Traders", Sharjah, UAE, were used. A 2-mm diameter hole was drilled close to the upper edge of the specimen and served to be hooked with a glass rod for immersion. Prior to each experiment, the specimens were polished with 600 grade emery paper, rinsed with distilled water, degreased with acetone, dried, and finally weighed precisely on an accurate analytical balance.

\section{Instrumentation}

A $250 \mathrm{~mL}$ round bottom flask fitted with a reflux condenser immersed in a thermally controlled water bath was used the weight-loss measurements with a long glass rod which served to hook and immerse the specimen. 


\section{Measuring procedure}

The flask was filled with $100 \mathrm{~mL}$ of $1.0 \mathrm{M} \mathrm{HCl}$ solution with and without VIPFA of various concentrations, then placed in water bath. As soon as the required working temperature was reached, the prepared mild steel sample was immersed in the solution, and left there for exactly six hours, after which the sample was removed, rinsed with distilled deionized water, degreased with acetone, dried, and finally weighed precisely on an accurate analytical balance. This procedure was repeated with all the samples with a variety of inhibitor concentrations ranging from $5.0 \cdot 10^{-7} \mathrm{M}$ to $5.0 \cdot 10^{-4} \mathrm{M}$; and at temperatures ranging from 303 to $343 \mathrm{~K}$.

\section{Results and discussion}

The weight loss corrosion tests were carried out on the mild steel in $1.0 \mathrm{M} \mathrm{HCl}$ in the absence and presence of VIPFA over a period of 6 hours. Table 1 shows the corrosion rates $\left[\mathrm{mg} \cdot \mathrm{cm}^{-2} \cdot \mathrm{h}^{-1}\right]$, and the percentage efficiencies [\%] for the studied inhibitor with concentrations varying from $5.0 \cdot 10^{-7} \mathrm{M}$ to $5.0 \cdot 10^{-4} \mathrm{M}$ at $303,313,323,333$, and $343 \mathrm{~K}$, respectively. The percentage efficiency was calculated according to the following expression:

$$
\% \text { Inhibition }=\frac{W_{U n i n h}-W_{\text {Inh. }}}{W_{\text {Uninh }}} \cdot 100,
$$

where: $\quad W_{\text {Uninh. }}=$ corrosion rate without inhibitor; and

$W_{\text {Inh. }}=$ corrosion rate with inhibitor.

Table 1. Effect of concentration of 1-vinylimidazole-3-phenacyl hexafluoroantimonate $(C)$ on the corrosion rate $\left(W, \mathrm{mg} \cdot \mathrm{cm}^{-2} \cdot \mathrm{h}^{-1}\right)$ and percentage efficiency $(E)$ of mild steel in $1.0 \mathrm{M} \mathrm{HCl}$ at various temperatures.

\begin{tabular}{|c|c|c|c|c|c|c|c|c|c|c|}
\hline \multirow{3}{*}{$C$} & \multicolumn{10}{|c|}{ Temperature / K } \\
\hline & \multicolumn{2}{|c|}{303} & \multicolumn{2}{|c|}{313} & \multicolumn{2}{|c|}{323} & \multicolumn{2}{|c|}{333} & \multicolumn{2}{|c|}{343} \\
\hline & $\boldsymbol{W}$ & $E$ & $\boldsymbol{W}$ & $E$ & $\boldsymbol{W}$ & $E$ & $\boldsymbol{W}$ & $\boldsymbol{E}$ & $\boldsymbol{W}$ & $\boldsymbol{E}$ \\
\hline 1.0 M HCl & 0.961 & - & 1.394 & - & 4.671 & - & 12.225 & - & 26.280 & - \\
\hline $\begin{array}{c}\text { 1.0 M HCl + } \\
5.0 \cdot 10^{-7} \mathrm{M}\end{array}$ & 0.447 & 53.3 & 0.815 & 41.5 & 3.238 & 30.7 & 9.559 & 21.8 & 23.310 & 11.3 \\
\hline $\begin{array}{c}1.0 \mathrm{M} \mathrm{HCl}+ \\
5.0 \cdot 10^{-6} \mathrm{M}\end{array}$ & 0.330 & 65.7 & 0.565 & 59.5 & 2.683 & 42.6 & 7.850 & 35.8 & 19.613 & 25.4 \\
\hline $\begin{array}{c}\text { 1.0 M HCl + } \\
5.0 \cdot 10^{-5} \mathrm{M}\end{array}$ & 0.151 & 84.3 & 0.280 & 79.9 & 1.560 & 66.6 & 5.708 & 53.3 & 14.434 & 45.1 \\
\hline $\begin{array}{c}1.0 \mathrm{M} \mathrm{HCl}+ \\
5.0 \cdot 10^{-4} \mathrm{M}\end{array}$ & 0.075 & 92.2 & 0.151 & 89.2 & 0.722 & 84.5 & 3.109 & 74.6 & 9.110 & 65.3 \\
\hline
\end{tabular}


Figures 1 and 2 show the plots of the corrosion rate of VIPFA as a function of concentration at $303,313,323,333$, and $343 \mathrm{~K}$. At $303 \mathrm{~K}$ (Figure 1) the corrosion rate dropped from $0.961 \mathrm{mg} \cdot \mathrm{cm}^{-2} \cdot \mathrm{h}^{-1}(1.0 \mathrm{M} \mathrm{HCl}$ in the absence of the inhibitor) to $0.447 \mathrm{mg} \cdot \mathrm{cm}^{-2} \cdot \mathrm{h}^{-1}\left(53.3 \%\right.$ inhibition) when $5.0 \cdot 10^{-7} \mathrm{M}$ of VIPFA was present in the $1.0 \mathrm{M}$ $\mathrm{HCl}$. This corrosion rate continued to decrease to reach $0.330 \mathrm{mg} \cdot \mathrm{cm}^{-2} \cdot \mathrm{h}^{-1}(65.7 \%$ inhibition) at a concentration of $5.0 \cdot 10^{-6} \mathrm{M}$, followed by a steep decrease to reach $0.151 \mathrm{mg} \cdot \mathrm{cm}^{-2} \cdot \mathrm{h}^{-1}(84.3 \%$ inhibition $)$ when the inhibitor's concentration was $5.0 \cdot 10^{-5} \mathrm{M}$; and finally, at higher concentration $\left(5.0 \cdot 10^{-4} \mathrm{M}\right)$ the corrosion rate slightly decreased to reach $0.075 \mathrm{mg} \cdot \mathrm{cm}^{-2} \cdot \mathrm{h}^{-1}(92.2 \%$ inhibition). At $313 \mathrm{~K}$ (Figure 1), the curve showed to have similar shape as that obtained at $303 \mathrm{~K}$. At concentrations greater than $5.0 \cdot 10^{-5} \mathrm{M}$, the corrosion rate decreased steeply and reached about $0.151 \mathrm{mg} \cdot \mathrm{cm}^{-2} \cdot \mathrm{h}^{-1}(89.2 \%)$ at $5.0 \cdot 10^{-4} \mathrm{M}$.

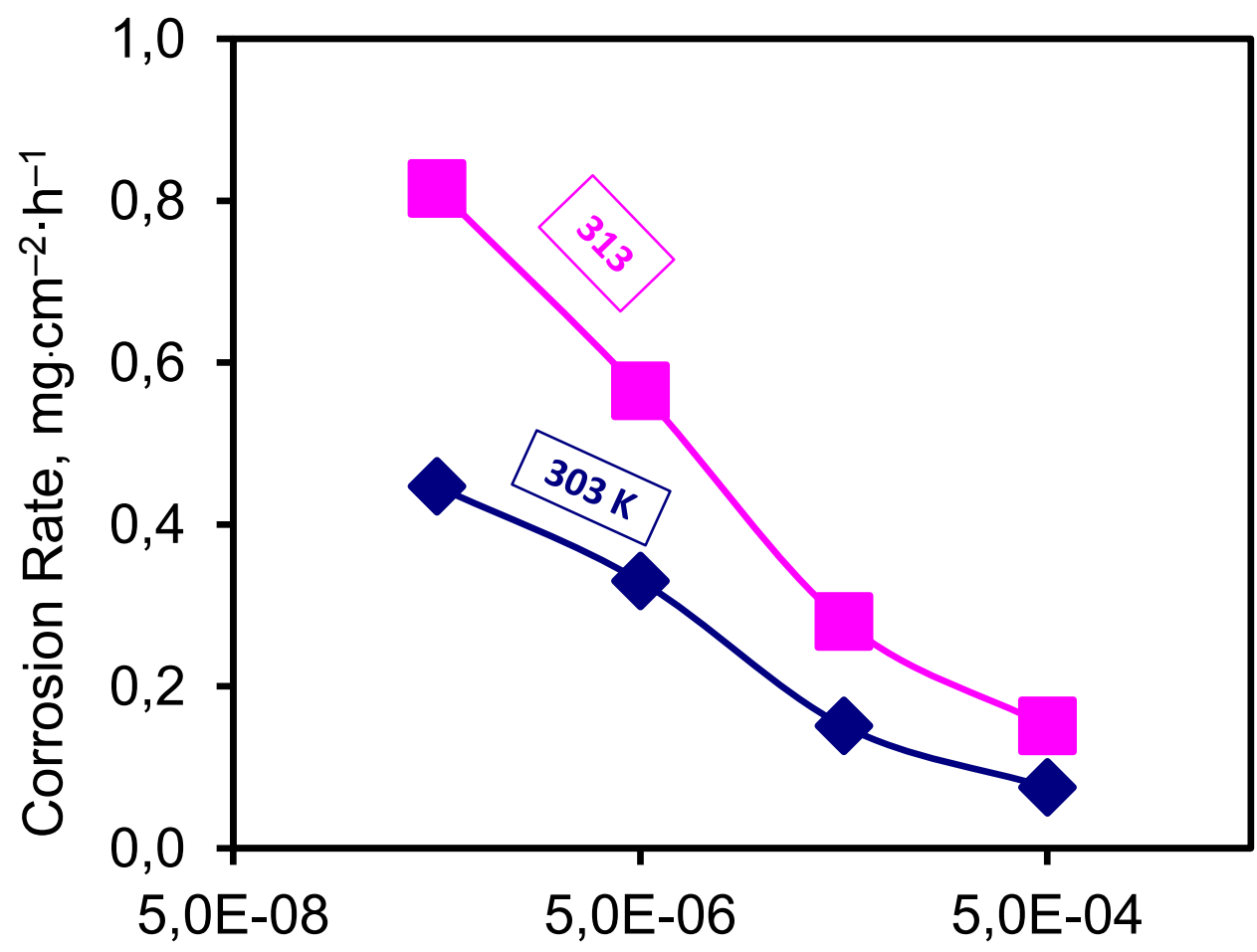

Concentration, $\mathrm{M}$

Figure 1. Effect of concentration of 1-vinylimidazole-3-phenacyl hexafluoroantimonate on the corrosion rate $\left(\mathrm{mg} \cdot \mathrm{cm}^{-2} \cdot \mathrm{h}^{-1}\right)$ of mild steel in $1.0 \mathrm{M} \mathrm{HCl}$ at various temperatures.

$303 \mathrm{~K}$; $313 \mathrm{~K}$.

At $323 \mathrm{~K}$ (Figure 2), the concentration of the inhibitor between $5.0 \cdot 10^{-7}$ and $5.0 \cdot 10^{-6} \mathrm{M}$ had very slight effect on the corrosion rate; whereas, at higher concentrations, the corrosion 
rate dropped from $2.683 \mathrm{mg} \cdot \mathrm{cm}^{-2} \cdot \mathrm{h}^{-1}$ (at $5.0 \cdot 10^{-6} \mathrm{M}$ ) down to 1.560 and $0.722 \mathrm{mg} \cdot \mathrm{cm}^{-2} \cdot \mathrm{h}^{-1}$ at $25.0 \cdot 10^{-5} \mathrm{M}$ and $5.0 \cdot 10^{-4} \mathrm{M}$, respectively.

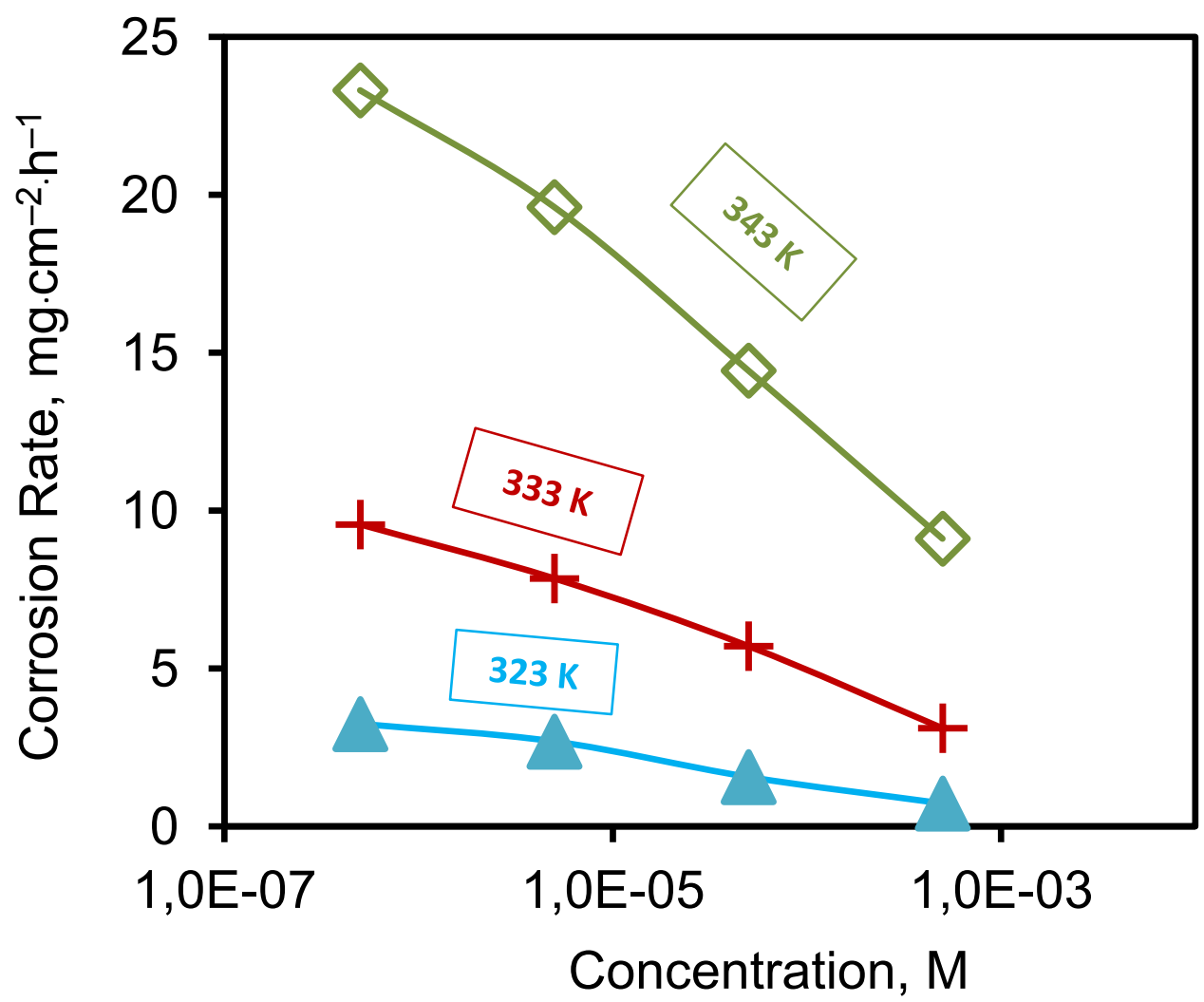

Figure 2. Effect of concentration of 1-vinylimidazole-3-phenacyl hexafluoroantimonate on the corrosion rate $\left(\mathrm{mg} \mathrm{cm}^{-2} \cdot \mathrm{h}^{-1}\right)$ of mild steel in $1.0 \mathrm{M} \mathrm{HCl}$ at various temperatures. $\boldsymbol{\Delta} 323 \mathrm{~K}$; $+333 \mathrm{~K} ; \diamond 343 \mathrm{~K}$.

The corrosion rates (Figure 2) at 333 and $343 \mathrm{~K}$ are shown respectively as a function of the concentration of VIPFA. It can be clearly seen that the presence of the VIPFA inhibitor at these high temperatures has acted as a corrosion inhibitor reaching a percent inhibition of $74.6 \%$ and $65.3 \%$ when $5.0 \cdot 10^{-4} \mathrm{M}$ inhibitor was employed at $333 \mathrm{~K}$ and $343 \mathrm{~K}$ respectively.

Figure 3 shows the plots of the $\%$ inhibition versus the concentration of the inhibitor at temperatures of $303,313,323,333$, and $343 \mathrm{~K}$, respectively. This figure showed that the $\%$ inhibition was greatly affected by the increase of temperature ( 303 to $343 \mathrm{~K}$ ), when all concentrations $\left(5.0 \cdot 10^{-7}\right.$ to $\left.5.0 \cdot 10^{-4} \mathrm{M}\right)$ of inhibitors were employed; and the presence of the inhibitor has greatly increased the $\%$ inhibition at all temperatures. 


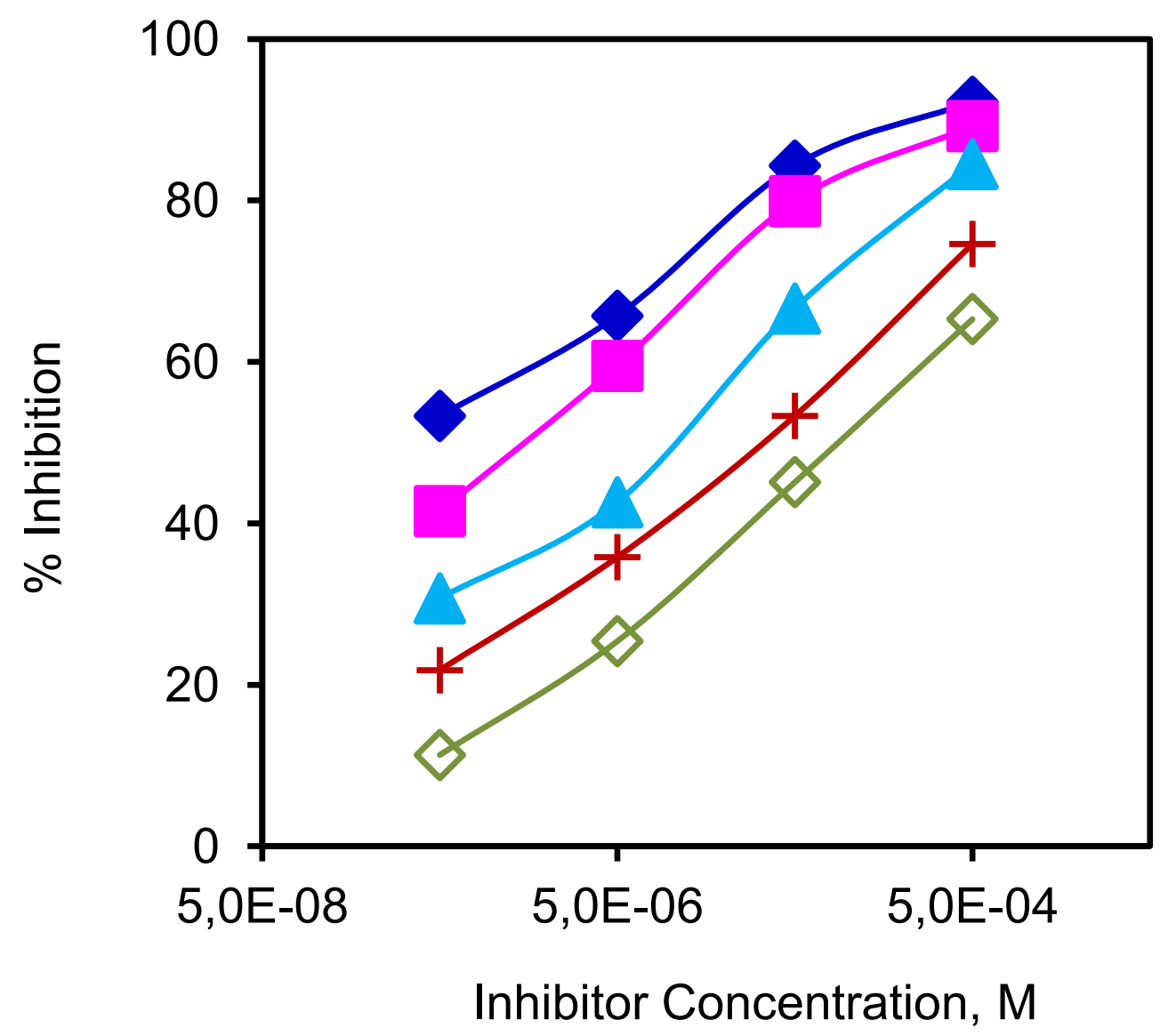

Figure 3. Effect of concentration of 1-vinylimidazole-3-phenacyl hexafluoroantimonate on the percent inhibition of mild steel in $1.0 \mathrm{M} \mathrm{HCl}$ at various temperatures. $303 \mathrm{~K}$; $313 \mathrm{~K}$;

А $323 \mathrm{~K} ; \mathbf{+} 333 \mathrm{~K} ; \diamond 343 \mathrm{~K}$.

The data obtained from the weight loss measurements (Table 1) were plotted in accordance to Arrhenius equation:

$$
\ln \text { rate }=-\frac{E_{a}}{R T}+\text { const }
$$

where: $\quad E_{\mathrm{a}}=$ activation energy $\left[\mathrm{kcal} \cdot \mathrm{mol}^{-1}\right], R=$ gas constant $\left[\mathrm{kcal} \cdot \mathrm{mol}^{-1}\right]$,

$T=$ absolute temperature $[\mathrm{K}]$, and const is a constant.

Figure 4 represents the Arrhenius plot of the corrosion of mild steel in $1.0 \mathrm{M} \mathrm{HCl}$ solution (Ln corrosion rate as a function of $1 / T$ ) with and without the presence of VIPFA at concentrations ranging from $5.0 \cdot 10^{-7} \mathrm{M}$ to $5.0 \cdot 10^{-4} \mathrm{M}$ (Table 2). From this Figure, the slope $\left(-\frac{E_{a}}{R}\right)$ of each individual line was determined and used to calculate the activation energy (Table 3) according to equation 2, and taking $R=1.987 \cdot 10^{-3} \mathrm{kcal} \cdot \mathrm{mol}^{-1}$. The 
increase of concentration of VIPFA (from $5.0 \cdot 10^{-7} \mathrm{M}$ to $5.0 \cdot 10^{-4} \mathrm{M}$ ), increased the activation energies for the corrosion of mild steel in $1.0 \mathrm{M} \mathrm{HCl}$ (initially $18.27 \mathrm{kcal} \cdot \mathrm{mol}^{-1}$ ) (Table 3). The increase in the activation energies for the corrosion is attributed to a decrease in the adsorption of the inhibitor on the metal surface as the temperature increased; and subsequently, an increase in the corrosion rate will result due to the greater exposed area of the metal surface to the acid.

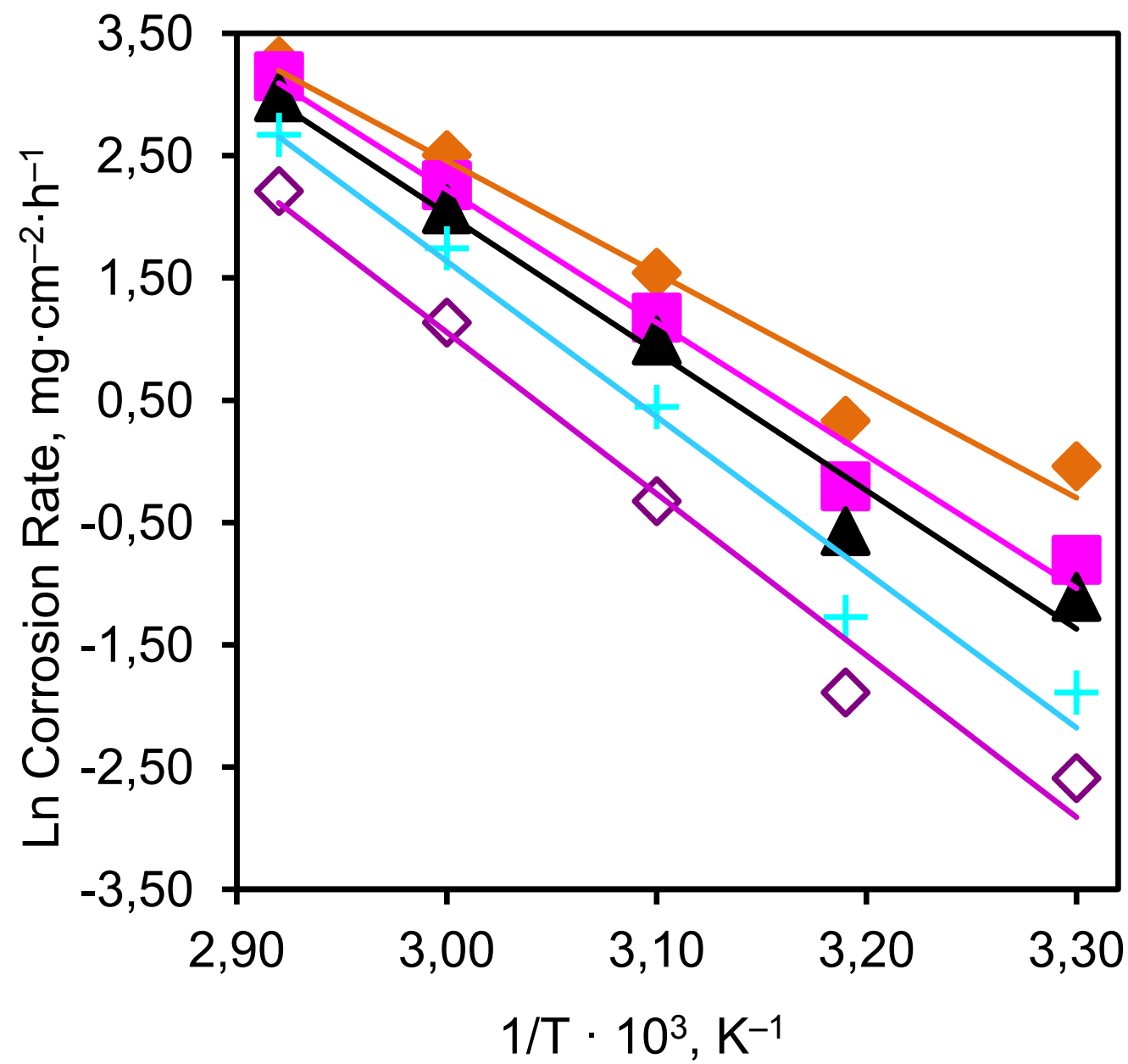

Figure 4. Effect of temperature on the corrosion rate of mild steel in $1.0 \mathrm{M} \mathrm{HCl}$ solution with and without the presence of various concentrations of 1-vinylimidazole-3-phenacyl hexafluoroantimonate. $\quad 1.0 \mathrm{M} \mathrm{HCl} ; \mathbf{\square} 5.0 \cdot 10^{-7} \mathrm{M} ; \boldsymbol{\Delta} 5.0 \cdot 10^{-6} \mathrm{M} ;+5.0 \cdot 10^{-5} \mathrm{M}$; $\diamond 5.0 \cdot 10^{-4} \mathrm{M}$.

The results in Table 3 show that the activation energy $\left(E_{\mathrm{a}}\right)$ for the corrosion of mild steel in the presence of the inhibitor are higher compared to the activation energy in the absence of inhibitor at all concentrations ranging from $5.0 \cdot 10^{-4} \mathrm{M}$ and $5.0 \cdot 10^{-7} \mathrm{M}$ (from about 26 to $22 \mathrm{kcal} \cdot \mathrm{mol}^{-1}$ ). This can be attributed to the fact that higher values of $E_{\mathrm{a}}$ in the 
presence of inhibitor compared to its absence are generally consistent with a physisorption [33].

Table 2. The data obtained from the weight loss measurements for Arrhenius equation: $(1 / T)$ against Ln Corrosion Rate.

\begin{tabular}{cccccc}
\hline & \multicolumn{5}{c}{ Ln Corrosion Rate $\left(\mathbf{m g} \cdot \mathbf{c m}^{-\mathbf{2}} \cdot \mathbf{h}^{-\mathbf{1}}\right)$} \\
\cline { 2 - 6 }$(\mathbf{1} / \boldsymbol{T}) \cdot \mathbf{1 0}^{\mathbf{3}} \mathbf{K}^{-\mathbf{1}}$ & $\mathbf{1 . 0} \mathbf{M ~ H C l}$ & $\begin{array}{c}\mathbf{1 . 0 ~ M ~ H C l}+ \\
\mathbf{5 . 0} \cdot \mathbf{1 0}^{-7} \mathbf{M}\end{array}$ & $\begin{array}{c}\mathbf{1 . 0} \mathbf{M ~ H C l}+ \\
\mathbf{5 . 0} \cdot \mathbf{1 0}^{-\mathbf{6}} \mathbf{M}\end{array}$ & $\begin{array}{c}\mathbf{1 . 0} \mathbf{M ~ H C l}+ \\
\mathbf{5 . 0} \cdot \mathbf{1 0}^{-\mathbf{5}} \mathbf{M}\end{array}$ & $\begin{array}{c}\mathbf{1 . 0} \mathbf{~ M ~ H C l}+ \\
\mathbf{5 . 0} \cdot \mathbf{1 0}^{-4} \mathbf{M}\end{array}$ \\
\hline 3.30 & -0.03978 & -0.8052 & -1.10866 & -1.89048 & -2.59027 \\
3.19 & 0.332177 & -0.20457 & -0.57093 & -1.27297 & -1.89048 \\
3.10 & 1.541373 & 1.17496 & 0.98694 & 0.44469 & -0.32573 \\
3.00 & 2.503483 & 2.25748 & 2.06051 & 1.74187 & 1.1343 \\
2.92 & 3.268808 & 3.14888 & 2.97619 & 2.66959 & 2.20937 \\
\hline
\end{tabular}

Table 3. The activation energy $\left(E_{\mathrm{a}}\right)$ for the corrosion of mild steel in $1.0 \mathrm{M} \mathrm{HCl}$ with and without 1 -vinylimidazole-3-phenacyl hexafluoroantimonate inhibitor at various concentrations.

\begin{tabular}{ccccc}
\hline \multirow{2}{*}{ System } & \multicolumn{4}{c}{ Activation energy, $\boldsymbol{E}_{\mathbf{a}}\left(\mathbf{k c a l} \cdot \mathbf{m o l}^{-\mathbf{1}}\right)$} \\
\cline { 2 - 5 } & $\mathbf{5 . 0} \cdot \mathbf{1 0}^{-\mathbf{4}} \mathbf{M}$ & $\mathbf{5 . 0} \cdot \mathbf{1 0}^{-\mathbf{5}} \mathbf{M}$ & $\mathbf{5 . 0} \cdot \mathbf{1 0}^{-\mathbf{6}} \mathbf{M}$ & $\mathbf{5 . 0} \cdot \mathbf{1 0}^{-\mathbf{7}} \mathbf{M}$ \\
\hline $1.0 \mathrm{M} \mathrm{HCl}$ & 18.27 & 18.27 & 18.27 & 18.27 \\
$1.0 \mathrm{M} \mathrm{HCl}+$ Inhibitor & 26.27 & 25.27 & 22.48 & 21.59 \\
\hline
\end{tabular}

Table 4. Effect of concentration of 1-Vinylimidazole-3-phenacyl hexafluoroantimonate on surface coverage $(\theta)$ for mild steel in $1.0 \mathrm{M} \mathrm{HCl}$ at various temperatures.

\begin{tabular}{cccccc}
\hline \multirow{2}{*}{$\begin{array}{c}\text { Concentration of } \\
\text { inhibitor }\end{array}$} & \multicolumn{5}{c}{ Temperature / K } \\
\cline { 2 - 6 } & $\mathbf{3 0 3}$ & $\mathbf{3 1 3}$ & $\mathbf{3 2 3}$ & $\mathbf{3 3 3}$ & $\mathbf{3 4 3}$ \\
\hline $1.0 \mathrm{M} \mathrm{HCl}+5.0 \cdot 10^{-7} \mathrm{M}$ & 0.535 & 0.415 & 0.307 & 0.218 & 0.113 \\
$1.0 \mathrm{M} \mathrm{HCl}+5.0 \cdot 10^{-6} \mathrm{M}$ & 0.657 & 0.595 & 0.426 & 0.358 & 0.254 \\
$1.0 \mathrm{M} \mathrm{HCl}+5.0 \cdot 10^{-5} \mathrm{M}$ & 0.843 & 0.799 & 0.666 & 0.533 & 0.451 \\
$1.0 \mathrm{M} \mathrm{HCl}+5.0 \cdot 10^{-4} \mathrm{M}$ & 0.922 & 0.892 & 0.845 & 0.746 & 0.653 \\
\hline
\end{tabular}

Table 4 shows the surface coverage of various concentrations of VIPFA (from $5.0 \cdot 10^{-7} \mathrm{M}$ to $5.0 \cdot 10^{-4} \mathrm{M}$ ) on mild steel surface as a function of temperature. These values were extracted from the corresponding \% efficiency values reported earlier in Table 1 . The plot of surface coverage, $\theta$, against the natural logarithm of the concentration, $\ln C$, for mild steel in the presence of the various inhibitor concentrations is shown in Figure 5. After examining the data and adjusting them to different theoretical adsorption isotherms, 
it was concluded that all inhibitors were adsorbed on the mild steel surface according to Temkin isotherm:

$$
-2 a \theta=\ln K C,
$$

where: $\quad a=$ molecular interaction constant,

$\theta=$ degree of coverage,

$K=$ equilibrium constant for the adsorption reaction, and

$C=$ concentration of the inhibitor.

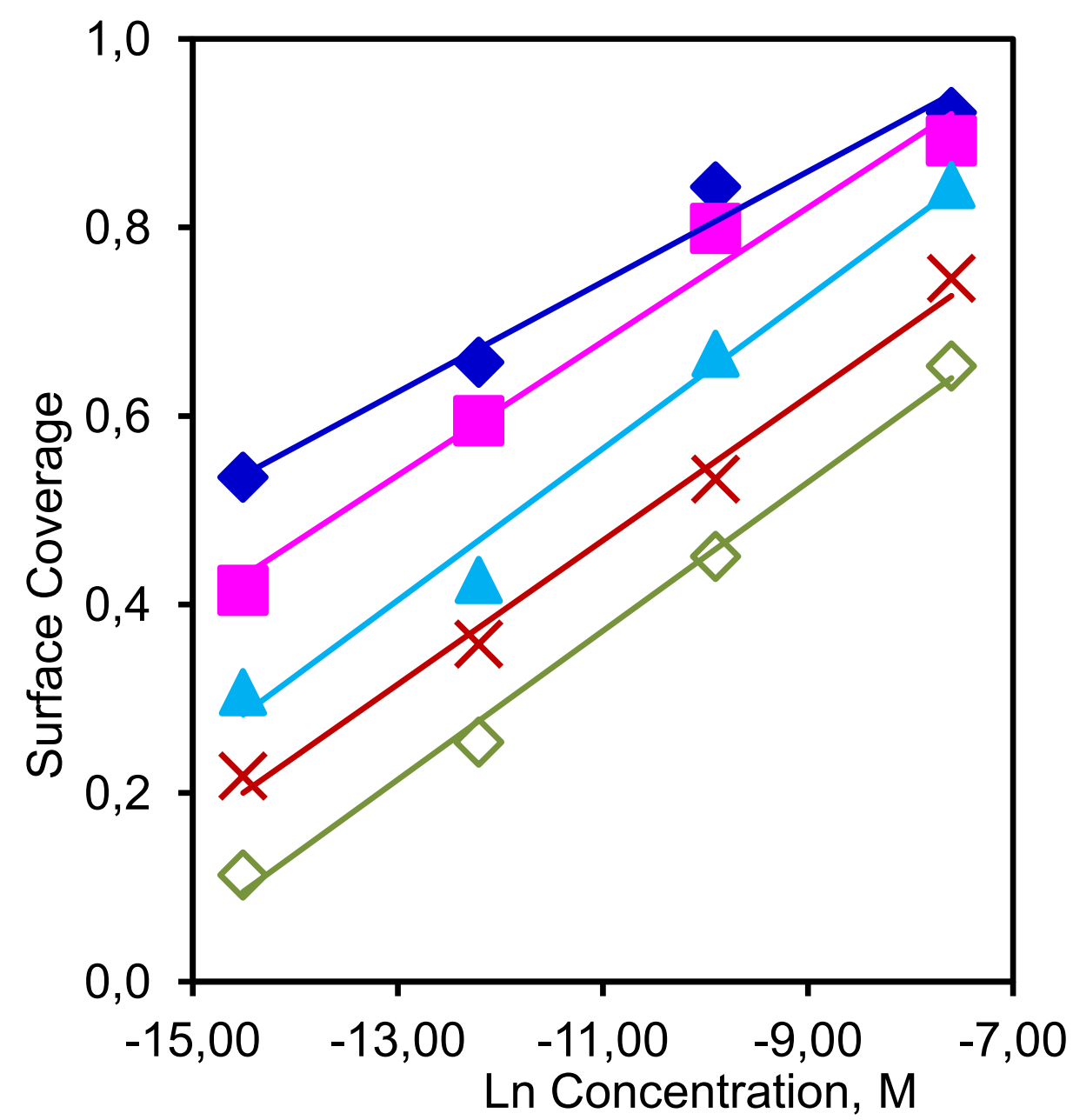

Figure 5. Effect of concentration of 1-vinylimidazole-3-phenacyl hexafluoroantimonate on the surface coverage of mild steel in $1.0 \mathrm{M} \mathrm{HCl}$ at various temperatures. $303 \mathrm{~K}$;

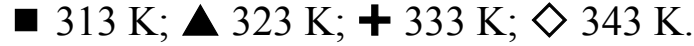

The equilibrium constant for the adsorption reaction, $K$, is related to the standard free energy of adsorption via the following equation given by Damaskin et al. [1]:

$$
K=\frac{1}{55.5} \exp \left(-\frac{\Delta G}{R T}\right)
$$


where: $\quad K=$ equilibrium constant for the adsorption reaction,

$55.5=$ concentration of water $\left[\mathrm{mol} \cdot \mathrm{L}^{-1}\right]$,

$\Delta G=$ standard free energy $\left[\mathrm{kcal} \cdot \mathrm{mol}^{-1}\right]$,

$R=$ gas constant $\left[\mathrm{kcal} \cdot \mathrm{mol}^{-1}\right]$, and

$T=$ absolute temperature $[\mathrm{K}]$.

According to Equation (3), the straight lines shown in Figure 5 will have the following slopes and intercepts:

$$
\begin{aligned}
\text { Slope } & =-\frac{1}{2 a} \\
\text { Intercept } & =-\frac{1}{2 a} \ln K .
\end{aligned}
$$

Combination of equations (5) and (6) leads to the following relationship:

$$
\text { Intercept }=\text { Slope } \cdot(\ln K),
$$

from which the equilibrium constant for the adsorption reaction, $K$, can be calculated:

$$
K=e^{\left(\frac{\text { Intercept }}{\text { Slope }}\right)}
$$

The standard free energy of adsorption of the inhibitor, $\Delta G^{0}$, can be calculated from the results in Figure 5 used to calculate the equilibrium constant, $K$, and Equation (4) at various temperatures ( 303 to $343 \mathrm{~K}$ ).

The enthalpy of adsorption, $\Delta H^{0}$, for the inhibitor can be calculated from the following equation:

$$
\Delta H^{0}=E_{\mathrm{a}}-R T
$$

The entropy change, $\Delta S^{0}$, can be calculated at various temperatures for the inhibitor using the following equation:

$$
\Delta G^{0}=\Delta H^{0}-T \Delta S^{0}
$$

Tables 5 to 7 show the thermodynamic data obtained in the presence of the inhibitor at $5 \cdot 10^{-4} \mathrm{M}$. These thermodynamic quantities represent the algebraic sum of the values for adsorption and desorption. The negative value of $\Delta G^{0}$ indicates the spontaneous adsorption of inhibitor on the surface of the mild steel. The standard free energy, $\Delta G^{0}$, varies from $-16.68 \mathrm{kcal} \cdot \mathrm{mol}^{-1} \cdot \mathrm{K}^{-1}$ at $303 \mathrm{~K}$ to $-13.44 \mathrm{kcal} \cdot \mathrm{mol}^{-1} \cdot \mathrm{K}^{-1}$ at $343 \mathrm{~K}$. The adsorption process is believed to be exothermic and associated with a decrease in entropy $(\Delta S)$ of solute, while the opposite is true for the solvent. The gain in entropy which accompanies the substitutional adsorption process is attributed to the increase in the solvent entropy. This agrees with the general suggestion that the values of $\Delta \mathrm{G}^{0}$ increase with the increase of inhibition efficiency $[34,35]$ as the adsorption of organic compound is accompanied by desorption of water molecules off the surface. 
Table 5. The enthalpy of adsorption $(\Delta H)$ for mild steel in $1.0 \mathrm{M} \mathrm{HCl}$ in the presence of $1 \cdot 10^{-3} \mathrm{M}$ 1-vinylimidazole-3-phenacyl hexafluoroantimonate at various temperatures $(303 \mathrm{~K}-343 \mathrm{~K})$.

\begin{tabular}{ccccc}
\hline \multicolumn{5}{c}{$\Delta \boldsymbol{H}, \mathbf{~ k c a l} \cdot \mathbf{m o l}^{-1}$} \\
\hline $\mathbf{3 0 3} \mathbf{~ K}$ & $\mathbf{3 1 3 ~ K}$ & $\mathbf{3 2 3 ~ \mathbf { ~ K }}$ & $\mathbf{3 3 3} \mathbf{~ K}$ & $\mathbf{3 4 3 ~ \mathbf { ~ }}$ \\
25.67 & 25.65 & 25.63 & 25.61 & 25.59 \\
\hline
\end{tabular}

Table 6. The free energy of adsorption $\left(\Delta G_{\text {ads }}\right)$ for mild steel in $1.0 \mathrm{M} \mathrm{HCl}$ in the presence of 1-vinylimidazole-3-phenacyl hexafluoroantimonate at various temperatures $(303 \mathrm{~K}-343 \mathrm{~K})$.

\begin{tabular}{ccccc}
\hline \multicolumn{5}{c}{$\Delta \boldsymbol{G}, \mathbf{~} \mathbf{~ c a l} \cdot \mathbf{m o l}^{-1}$} \\
\hline $\mathbf{3 0 3 ~ K}$ & $\mathbf{3 1 3 ~ K}$ & $\mathbf{3 2 3 ~ K}$ & $\mathbf{3 3 3 ~ K}$ & $\mathbf{3 4 3 ~ K}$ \\
-16.68 & -15.28 & -14.14 & -14.00 & -13.44 \\
\hline
\end{tabular}

Table 7. The change in entropy $(\Delta S)$ for mild steel in $1.0 \mathrm{M} \mathrm{HCl}$ in the presence of 1-vinylimidazole-3phenacyl hexafluoroantimonate at various temperatures (303 K - $343 \mathrm{~K})$.

\begin{tabular}{|c|c|c|c|c|}
\hline \multicolumn{5}{|c|}{$\Delta S, \mathrm{kcal} \cdot \mathbf{K}^{-1} \cdot \mathrm{mol}^{-1}$} \\
\hline $303 \mathrm{~K}$ & $313 \mathrm{~K}$ & $323 \mathrm{~K}$ & $333 \mathrm{~K}$ & $343 \mathrm{~K}$ \\
\hline 0.140 & 0.131 & 0.123 & 0.119 & 0.114 \\
\hline
\end{tabular}

The high inhibition efficiency may be attributed to the preferred flat orientation of this compound on the metal surface. The interaction occurs between the delocalized $\pi$-electrons of the two aromatic rings (imidazole and phenyl), the vinyl double bond $(-\mathrm{C}=\mathrm{C}-)$, and the lone pair of electrons on heteroatoms $(\mathrm{N}$ and $\mathrm{O})$ with the positively charged metal surface.

\section{Conclusion}

1-Vinylimidazole-3-phenacyl hexafluoroantimonate salt (VIPFA) was found to be a very efficient inhibitor for mild steel in $1.0 \mathrm{M} \mathrm{HCl}$ solution, reaching about $92 \%$ at $5.0 \cdot 10^{-4} \mathrm{M}$ at $303 \mathrm{~K}$, a concentration which is considered to be very moderate.

1-Vinylimidazole-3-phenacyl hexafluoroantimonate salt is a potential corrosion inhibitor since it contains not only a nitrogen atom, but also two aromatic rings (imidazole and phenyl). It was apparent from the molecular structure that this conjugated compound would be adsorbed onto the metal surface through the lone pair of electrons of nitrogen and oxygen, and $\pi$-electrons of the two aromatic rings as well as the double bond that is attached to the imidazole ring. The percentage inhibition in the presence of this inhibitor decreased with the increase of temperature, which indicated that physical adsorption was the predominant inhibition mechanism. 


\section{References}

1. B. B. Damaskin, O. A. Petrii and W. W.Batrakov, Adsorptsiya organicheskikh soedinenii na electrodakh (Adsorption of organic compounds on electrodes), Moscow, Nauka, 1968 (in Russian).

2. G. Okamato, M. Nagayama, J. Kato and T. Baba, Corros. Sci., 1962, 2, no. 1, 21.

3. M. Ibrahim, M. Messali, Z. Moussa, A. Y. Alzahrani, S. N. Alamry and B. Hammouti, Portug. Electrochim. Acta, 2011, 29, no. 6, 375. doi: 10.4152/pea.201106375

4. A. Popova, M. Christov, S. Raicheva and E. Sokolova, Corros. Sci., 2004, 45, no. 6, 1333.

5. A. Popova, M. Christov and T. Deligeorgiev, Corrosion, 2003, 59, no. 9, 756.

6. A. Popova, E. Sokolova, S. Raicheva and M. Christov, Corros. Sci., 2002, 45, no. 1, 33.

7. A. Popova and M. Christov, Corros. Sci., 2006, 48, no. 10, 3208.

8. I. Sekine, Y. Nakata and H. Tanabe, Corros. Sci., 1988, 28, no.10, 987.

9. A. Popova, M. Christov A. Vasilev, Corros. Sci., 2015, 94, 70.

10. A. Nahlé, I. Abu-Abdoun and I. Abdel-Rahman, Anti-Corros. Meth. Mater., 2008, 55, no. $4,217$.

11. H. Zhao, Chem. Eng. Commun., 2006, 193, no. 12, 1660.

12. S. M. Beloglazov, Z. I. Dzhafarov, V. N. Polyakov and N. N. Demushin, Prot. Met. USSR, 1991, 27, no. 6, 810 .

13. A. V. Fokin, M. V. Pospelov and A. N. Levichev, Prot. Met. USSR, 1983, 19, no. 2, 242.

14. A. Nahlé, Corr. Prev. Contr., 1997, 44, no. 7, 99.

15. A. Nahlé, Corr. Prev. Contr., 1998, 45, no. 4, 124.

16. A. Nahlé, Bull. Electrochem., 2002, 18, no. 3, 105.

17. A. Nahlé and F. C. Walsh, Corr. Prev. Contr., 1995, 42, no. 2, 30.

18. B. V. Savithri and S. M. Mayanna, Ind. J. Chem. Technol., 1996, 3, no. 5, 256.

19. L. D. Skrylev, E. A. Streltsova and T. L. Skryleva, Prot. Met. USSR, 1991, 27, no. 6, 755.

20. T. Vasudevant, S. Muralidharan, S. Alwarappan and S. V. K. Iyer, Corros. Sci., 1995, 37, no. 8, 1235 .

21. H. Ashassi-Sorkhabi and M. Es'haghi, Mater. Chem. Phys., 2009, 114, no. 1, 267.

22. O. Olivares-Xometl, N. V. Likhanova, M. A. Dominguez-Aguilar, E. Arce, H. Dorantes and P. Arellanes-Lozada, Mater. Chem. Phys., 2008, 110, no. 2-3, 344.

23. Q. B. Zhang and Y. X. Hua, Electrochim. Acta, 2009, 54, no. 6, 1881.

24. R. Gasparac, C. R. Martin and E. Stupnisek-lisek, J. Electrochem. Soc., 2000, 147, no. 2, 548-551.

25. S. Muralidharan and S. V. Lyer, Anti-Corros. Meth. Mater., 1997, 44, no. 2, 100.

26. I. Lozano, E. Mazario, C. O. Olivares-Xometl, N. V. Likhanova and P. Herrasti, Mater. Chem. Phys., 2014, 147, no. 1-2, 191.

27. A. L. Chong, M. Forsyth and D. R. MacFarlane, Electrochim. Acta , 2015, 159, 219.

28. M. Cai, Y. Liang, F. Zhou and W. Liu, Wear, 2013, 306, no. 1-2, 197. 
29. Q. Wang and C. Fu, Fushi Kexue Yu Fanghu Jishu, 2012, 24, no. 4, 319.

30. Q. Meng, Y. Zhang, H. Yan, W. Huang and Y. Cong, Yufeng Yingyong Huagong, 2011, 40, no. 8, 1416.

31. Y. Yin, R. Liu, X. Wang and L. Zhu, Zhongguo Fushi Yu Fanghu Xuebao, 2008, 28, no. $5,291$.

32. W. Fristad, H. Rossnaier and H. Moeller, Ger. Offen., DE 4041173 A1 1992062, 1992.

33. A. Popova, Corros. Sci., 2007, 49, no. 5, 2144.

34. A. S. Fouda, A. Abd El-Aal and A. B. Kandil, Anti-Corros. Meth. Mater., 2005, 52, no. $2,96$.

35. A. S. Fouda, M. N. Mousa, F. I. Taha and A. I. Elneamaa, Corros. Sci., 1986, 26, no. 9, 719.

36. L. E. Tsygankova, V. I. Vigdorovich, N. V. Shel and E. V. Dubinskaya, Int. J. Corros. Scale Inhib., 2013, 2, no. 4, 304. doi: 10.17675/2305-6894-2013-2-4-304-310

37. I. A. Zaafarany, Int. J. Corros. Scale Inhib., 2014, 3, no. 1, 12. doi: 10.17675/23056894-2014-3-1-012-027

38. I. A. Arkhipushkin, L. I. Yesina, Yu. Ya. Andreev, L. P. Kazansky and Yu. I. Kuznetsov, Int. J. Corros. Scale Inhib., 2012, 1, no 2, 107. doi: 10.17675/2305-6894-2012-1-2$\underline{107-116}$ 